\title{
Drone Applications for Preventing and Responding HAZMAT Disaster
}

\author{
Agoston Restas \\ Institute of Disaster Management, National University of Public Service, Budapest, Hungary \\ Email: Restas.Agoston@uni-nke.hu
}

How to cite this paper: Restas, A. (2016) Drone Applications for Preventing and Responding HAZMAT Disaster. World Journal of Engineering and Technology, 4, 7684 .

http://dx.doi.org/10.4236/wjet.2016.43C010

Received: July 21, 2016

Accepted: September 25, 2016

Published: September 28, 2016

\begin{abstract}
Introduction: This article describes some possibilities of drone applications for preventing and responding hazardous materials disasters. Methods: Apart from reviewing the little professional literature available, the author relied on his own practical experience and adopted other researchers' related findings. He also applied logical reasoning, systematization as well as adopting an economic approach-to assess efficiency. Results: There are two basic possibilities for the use of drones in the field of chemical disasters: one is for prevention to support the work of authorities, while the other is connected to the response to accidents or disasters. To summarize the research findings, the author explored the typical possibilities for use, illustrating with actual examples to prove their usefulness, identified certain risks and made recommendations on further researches.
\end{abstract}

\section{Keywords}

Drone, Hazardous Materials, HAZMAT Disaster, Industrial Safety, Authority Inspection, Effectiveness, 3D Imagery

\section{Introduction}

A general characteristic of disaster responses is that the available resources of the organizations in charge are limited or even scarce. To overcome this lack, the possible application of every new equipment or method has to be considered. If from both professional and economical viewpoints, the new equipment or method is considered effective; its introduction is not just a possibility but a moral obligation-to meet society's expectations. There have already been many international examples of drone applications in the field of fire protection [1]-[3] though; the management in case of chemical accidents or industrial safety is still just exploring the possibilities. 
It is not by mistake that we differentiate between professional and economic effectiveness. To illustrate it with an example-of technical nature, similar to that of the drone, from a professional viewpoint, no doubt it would be more effective to double the number of Disaster Management Operational Laboratories (hereinafter: DiMOL), because in some cases it would allow quicker and more accurate decisions. However, somebody-ultimately the society-has to bear its costs. If a double number of DiMOLs and quicker, more accurate decisions resulted in a less damages and more saved value than the costs of DiMOLs, the criterion of professional efficiency as well as that of economic efficiency would be met. Generally, for professionals within certain organizations, the former factor is more decisive while the latter is ignored or it is taken for granted, but it is not necessarily true for the society. If professionals manage to prove that the second criterion is also met, then decision-makers-as representatives of the society-have no other rational choice but accept it. This idea could be further elaborated on [4] [5], but this paper does not address it. To sum up, the first criterion-professional effectiveness-is essential but not sufficient to meet the criterion of economic effectiveness, but the second one necessarily involves that the first criterion is satisfied.

\section{Drone Applications for Preventing HAZMAT Disaster}

There are several opportunities to employ drones in chemical industry. A basic principle can be that whenever a traditional aircraft can prove to be useful, drone can be a benefit, too. Obviously, not all traditional aircraft uses can be substituted, but the author believes that the rate of potential applications of drone is on the rise due to technological development. Based on experience, the spread of drone is expected to reduce the costs of aerial applications, so by following the previous train of thought, we can conclude that drone could also be used in cases where traditional aerial reconnaissance was not previously considered owing to its high costs although its effectiveness was never doubted. In other words, drone could not simply substitute traditional aircrafts, but could also open new dimensions for aerial reconnaissance, where previously there have been no precedents. The applications in the field of chemical industry (in wider the industrial safety) could be a typical example for this.

Among preventive actions, drone can primarily be applied in inspections, which could increase effectiveness of the current practice, supplement it or could even lead to the introduction of new methods. In the following, the author describes actual possibilities, although some details (e.g. preparation of the flight, applying for permits to fly, data protection) cannot be discussed due to length limits.

\subsection{Surveillance and Aerial Inspection for Transport}

Inspection of dangerous goods transport is a marked task in the field of industrial safety. On the one hand, it can ensure compliance of the transporters and on the other, it can reduce environmental impact of the transportation and even direct risk of danger or pollution. An advantage of inspections backed by drone aerial reconnaissance is that they can remain completely hidden. Partial inspection of the vehicle carrying dangerous 
goods can happen statically at one point without disturbing the traffic or even repeatedly and dynamically, which allows supervising the driver and his compliance with the Highway Code. A further advantage is that it can be applied with three out of the four means of transportation: road, rail and water. In addition to the current practice of a single, static inspection, it can be intermittent or continuous as well in unique, special cases (e.g. with radioactive materials). Finally, in water transport, preventive steps might be more effective with preliminary assessment (aerial inspection) and hidden inspections.

It also needs to be considered that drone backed inspection is not a substitute to traditional ways of inspections-even if it may evolve to be a separate one in the futurebut rather a complementary that increases effectiveness of prevention. Drone is not justified in every case, yet its regular application would represent a qualitative change both in inspections and in the law-abiding conduct of transporters. However, its undue application or overstatement of its advantages may lower the quality and effectiveness of traditional inspections, so its expert planning requires thorough consideration.

\subsection{Inspection of Dangerous Establishments}

Authorities can perform inspections of dangerous establishments in accordance with legislations. The presence of authorities can interfere with the normal operation of the establishments-even if they were informed in advance. Despite this, inspections are only able to assess a certain state even though rigorous requirements are set out for transparent processes. If the legal framework is created for aerial reconnaissance of industrial facilities, authority inspections can be performed partly or fully hidden, without disturbing the operation in the facility. Aerial reconnaissance could be regular, more frequent than previously. In case of pre-notified inspections, a more complex picture can be created based on a geo-information database, which provides conclusive information on the actual state of storage and its changes over time. In addition, aerial reconnaissance could easily extend beyond the fences of the facility and also map its impacts on the environment. With the help of geographical information systems, a so-called pollution history can be created, which archives pollutants linked to a time scale.

\subsection{Supervision of Compliance with Technological Requirements}

When industrial facilities are built, expanded or renovated, authorities strive to guarantee a state of the art level of safety by fully enforcing the requirements. Its expenses are borne by the owner, who-trying to cut costs with non-compliant practices-might occasionally deviate in quality from the authority requirements. Obviously, such cost-cutting practices might be applied by the contractors, without the operator being aware of it. They are rather difficult to discover but aerial reconnaissance with highresolution cameras can be of great help. It is especially true for investments that cannot be inspected or only to a limited extent once they are ready.

Inspections can be either pre-notified or unannounced. Drone applications also al- 
low to archive images for later uses, e.g. for evidence. Possibilities abound and can be tailored to the clients' requests. Even so, aerial reconnaissance can only be applied in line with legislation, which is not yet detailed enough for drone applications. Characteristics of the given task, privacy rights and data protection have to be considered along with the pre-determined goals of the flight, which cannot be diverged from. In most cases, camera range is wider than necessary, but the so-called electronic masking can overcome this problem. Obviously, impacts of a dangerous establishment might extend beyond its fences, so aerial footage can be beneficial in these cases yet again.

\section{Drone Applications for Responding HAZMAT Disasters}

\subsection{Accidental Release of Dangerous Substance}

Drone application with accidental leakage of dangerous substances is in many ways similar to interventions in nuclear disasters. Often times, the site is hardly accessible, the severity of the accident cannot be properly determined without reconnaissance, responders can only approach the site in the appropriate protective clothing, there is a high risk of intoxication, combustion and explosion and secondary dangers might also develop (dangers caused by structural damages from explosions, domino effect).

Responders arriving first to the scene-most often, professional fire fighters-put on breathing apparatus and protective clothing against chemicals as well, in line with the default procedure of reconnaissance. Gearing up can be a substantial loss of time and protective clothing can often hinder movement or even accurate reconnaissance. Experience with forest fires show that with drone application professionals are quicker to gather vital information than on foot [6]. Unloading and preparing the protective clothing, putting on the breathing apparatus and gearing up along with activating the measuring devices obviously take more time, the author presumes at least a five-minute delay even with experienced fire fighters. Depending on the dangerous substance and the nature of the accident, the size of safety perimeter can vary, but at least a distance of $100 \mathrm{~m}$ has to be kept; meaning, it is the closest vehicles can approach the scene. Assuming a departure point close to the minimum (approx. $120 \mathrm{~m}$ ) and that the average speed of geared up reconnaissance units is $\max 1 \mathrm{~meter} / \mathrm{min}$, we can calculate with an additional delay of at least 2 minutes while they get to the scene from the vehicle. A greater distance would mean a proportionately longer delay and wind direction and other obstacles on the route would also add to the duration of the traditional reconnaissance. In chemical accident a seven-minute delay can be expected if the units arriving first to the scene carry out traditional reconnaissance to gain accurate information.

\subsection{Theoretical Principles of Effective Drone Application}

Effective drone application in the above case demands that several conditions are met at the same time. One is that information provided by drone has to be quicker than traditional reconnaissance. Based on the above, its tipping point is at the minimal extreme value, about 7 minutes, so if drone can provide information within this period of time, 
it is more effective than the traditional solution. Based on the wildfire experiences, drone can stay within that time frame [6], so this condition favors drone over traditional reconnaissance even at its best. In case of longer distances, the difference is more pronounced, since airspeed is obviously higher than walking speed, thus drone gains time.

The other condition is that the information provided by the drone has to be of appropriate quality. Appropriate quality does not entail that it has to be at least as good as the one coming from traditional reconnaissance-although it might be of even better quality-but rather that the incident commander can rely on them to make quick and professional decisions. Drone application must not put the decision and the intervention themselves at a disadvantage either in time or quality. On the whole, information gathered by drone has to fulfil the minimum requirements of effective reconnaissance.

Naturally, further conditions have to be met as well. Drone application can apply only so much human resources (fire fighters with drone pilot qualification) that does not hinder the intervention and does not pose a risk to its effectiveness. In other words, the intervention does not miss the engaged resources or it pays off due to the information drone provides.

There are further conditions, which are not dealt with in this paper: weather conditions are fit for flights (e.g. wind speed, visibility), permits to fly are available, pilots are qualified for the task and decisions based on the reconnaissance are professionally effective. However, the changes in risks caused by drone application definitely need to be addressed; it can either increase or decrease risks of the intervention.

Advantages of drone application are generally explained with the fact that it can fly as close as 0.5 meter to the site and relay images [7]. When an unknown material is released, too close observation should be avoided because of the potential risk of explosion. This risk is due to the fact that drone is electric powered and arcing and sparks are its natural results, which may be sources of ignition in this environment. Therefore, flying too close to the leakage is to be avoided.

Other risks can emerge as well: secondary dangers resulting from malfunctioning of the drone, inexperienced use or too much preference for drone application (human factor). It has to be added that other risks, in turn, obviously decrease: exposure to pollutants, risk of accidents, etc. The dangers of drone need analyzing in detail, for which the author recommends a SWOT analysis.

Typical risks with drone in the situations above are flying in the presence of unknown substances and the risk of explosion. In order to avoid them and to increase effectiveness of reconnaissance, it would be beneficial to determine precisely the spread of the released material. Currently, reconnaissance relies on the measure of DiMOLs, which although may be useful, it still has certain weaknesses. On the one hand, it arrives later at the scene than the alerted fire fighters almost without exception, so its measures cannot help in the first phases of the intervention; on the other hand, DiMOL usually carries out measures at a single point, whose reliability even with three-dimensional spread models is not high. This latter criticism can only be relevant in case of an 
actual problem, otherwise in most cases dangerous substances are released only in small amounts and become easily diluted before they reach the problematic threshold value (lower explosive limit, intoxication or even perceptibility). Substances lighter than the air do not even cause any problems closer to the source.

Transforming a single-point (one-dimensional) measure into a three-dimensional space obviously would not be unreasonable. Practically, this is how currently modelling works: according to the data entered (measured), the spread of the material is estimated in a three-dimensional space. Displaying the typical or desirable extreme values will yield a so-called rheological curve, which can help decide on the necessary measures. However, there might be substantial differences between the actual and the predicted spread, and certainly the model allows a certain extent of tolerance that guarantees a higher degree of safety for the decision-maker. If the model is closer to the actual spread, the intervention can be more effective, the necessary measures can be issued earlier or the unnecessary ones can be avoided (e.g. unnecessary evacuation).

\subsection{D Spread of Vapors and Gases of Dangerous Materials}

In view of the above, the spreading of vapors and gases of dangerous materials needs to be measured and there have already been examples of it. Devices installed on boards that are able to measure various substances can also display actual a three-dimensional model of the gaseous dangerous material. Data is provided by various sensors installed on the aircraft and it is recorded in a complex coordinate system. Here the measured values are assigned to geographical coordinates of the flight, which supplemented by altitude, outlines the spatial location of the given substance [8]. These data can supplement the values based on the models and also serve as their suitability indices to check the accuracy of calculation algorithms.

Figure 1 shows a rotary wing drone able to detect gases, which measured the level of carbon dioxide and nitric oxide. Geographical coordinates of the flight and the associated carbon dioxide concentrations are shown in the adjacent functions. The values supplemented with altitude can display the calculated values in three dimensions, as it can be seen in Figure 2, which shows the previous carbon dioxide measurement as well as another test flight for measuring nitric oxide.

\section{Conclusions}

Based on the author's research, drone can be applied also in industrial safety within the field of disaster management. Basically, there are two ways for this: to support preventive measures of the authorities and in response to accidents involving dangerous substances. It has to be noted with both ways that drone application is not a substitute for the protocol currently used but a complementary to it, even if drone applications designed specifically for industrial safety are developed and introduced in the future. Related research is only in its initial stage, so this paper focuses on exploring the opportunities and refrains from legal, organizational or preparedness issues that hinder drone application. Separate studies are needed to address these issues. 

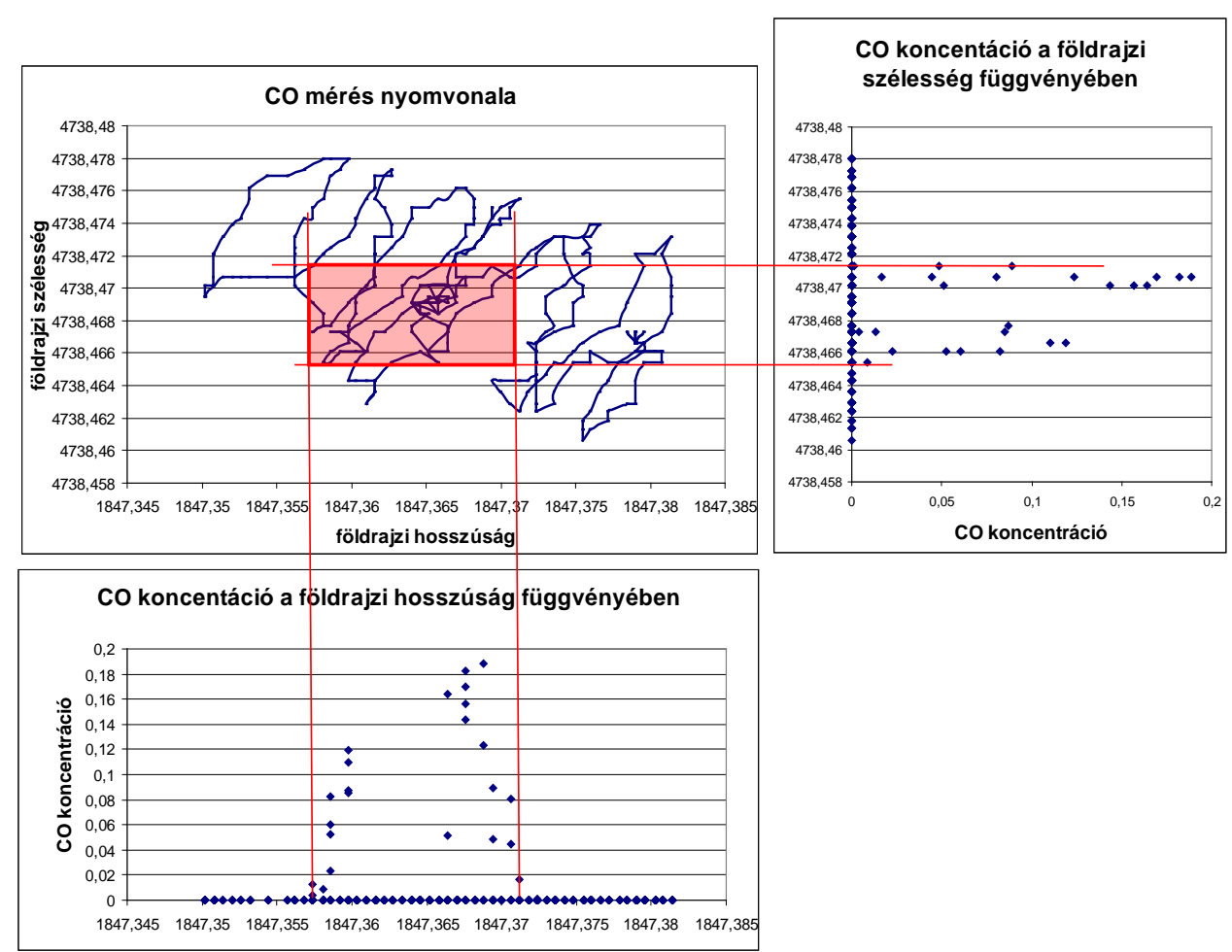

Figure 1. Geographical coordinates of a test flight, functions of carbon dioxide concentrations and the rotary-wing drone performing the measures with sensors installed on board [8].
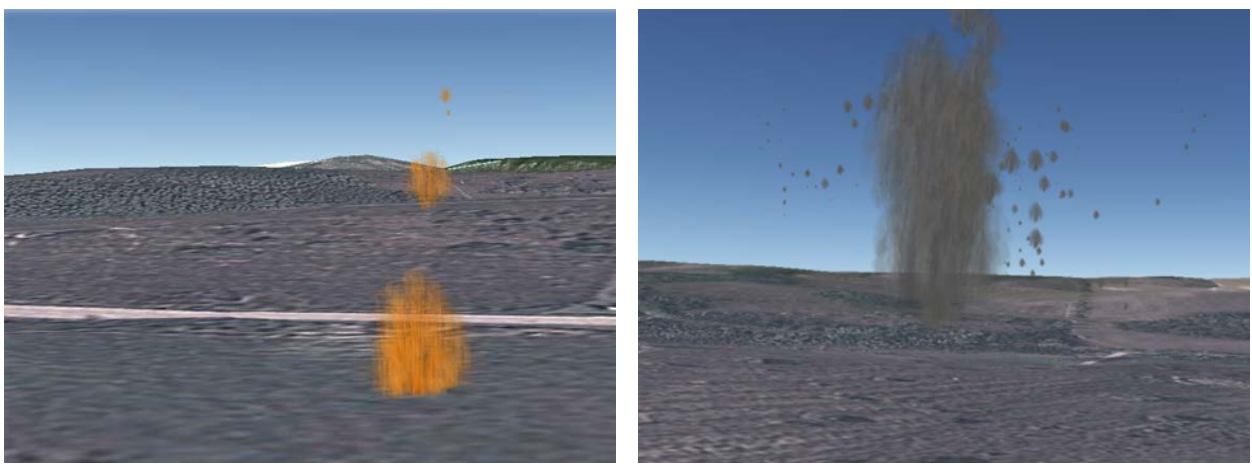

Figure 2. Graphic representations of carbon dioxide and nitric oxide clouds as the results of the test flight measurements [8].

The paper described the support drone application can provide to the authorities to inspect dangerous goods transport and prevent incidents. To supplement current practice, static inspection of a given state of vehicles could become dynamic and they could stay partly or even fully hidden with the help of drone application. In the author's opinion, it would be especially beneficial with transport by water. The current practice of inspecting industrial facilities can be supplemented with drone application in parallel with traditional inspections or with regularly captured preliminary images to show potential pollution and to create and document a so-called pollution history. Hidden inspections could also be aimed at checking technological discipline. To sum up, drone 
application in the field of industrial safety promotes law-abiding conduct by supporting preventive efforts, thus it leads to a lower risk of accidents.

Drone can also be considered in the response to incidents involving dangerous substances. Primary responders may be aided with aerial reconnaissance carried out by drone, its application minimize or eliminate exposure of responders during reconnaissance and recovery. Preliminary flight plans are vital even if speed and promptness is among the priorities. The paper also draws attention to potential risks and the dangers of overemphasizing drone.

Effective drone application for reconnaissance has multiple requirements. On the one hand, (visual) information gathered by drone has to meet the minimum requirements of effective reconnaissance and on the other hand, it needs to be at least as quick as traditional reconnaissance. This latter condition is easy to fulfil based on the author's research and minimum duration is approximately 7 minutes. There are further conditions as well, which this paper just touched upon.

The decisions based on reconnaissance can be justified if the spread model for the dangerous substance corresponds to reality. As a complementary to current practices, the author recommends that necessary measures (e.g. population protection) take into account actual spread based on drone information instead of the spread modelling. Above findings of the study do not intend to offer an exhaustive list of potential drone applications in the field of hazardous materials but rather to bring the topic into the attention of those interested and to encourage further studies.

Above research was supported by the project titled: "Public Service Development Establishing Good Governance, PADOP-2.1.2-CCHOP-15-2016-00001" at the National University of Public Service, Budapest, Hungary.

\section{References}

[1] Restas, A. (2004) Erdőtüzek felderítésének támogatása levegőből (Supporting Reconnaissance of Forest Fires from the Air). Vedelem, 11, 47-49.

[2] Ambrosia, V., Hinkley, E., Brass, J.A., Buechel, S., Sullivan, D., Myers, J. and Schoenung, S. (2006) The Western States UAV Fire Mission; 11th Biennial USDA Forest Service, Remote Sensing Applications Conference RS-2006, April 24-28 2006, Salt Lake City, Utah.

[3] Pastor, E., Royo, P., Lopez, J., Barrado, C., Santamaria, E. and Prats, X. (2008) Project SKY-EYE, Applying UAVs to Forest Fire Fighter, Support and Monitoring; Technical University of Catalonia, Department of Computer Architecture, Barcelona.

[4] Restas, A. (2011) Az erdőtűzoltás hatékonyságának közgazdasági megközelítése (The Economic Approach of the Efficiency of Forest Fire Fighting). Vedelem, 18, 47-50.

[5] Restas, A. (2012) An Approach for Measuring the Economic Efficiency of UAV Applications at Forest Fires Helping Decision Makers; AUVSI Israel 2012, International Conference, 20-22 March 2012, Tel Aviv.

[6] .Restas, A. (2006) The Regulation Unmanned Aerial Vehicle of Szendrő Fire Department Support Fighting Against Forest Fire; V International Conference on Forest Fire Research, 27-30 November, 2006, Figueira da Foz.

[7] Mika, P. (2009) Emergency Service Use of UAS West Midlands Fire Service, UAS Yearbook, 2009/2010 [Edit. Blyenburgh,] UAS-The Global Perspective, Paris, 137-139. 
[8] Molnar, A. (2014) UAV alkalmazások fejlesztése az Óbudai Egyetemen (Development of UAV Applications at Óbuda University), Critical Infrastructure Protection Researches, Conference Presentation, Szolnok, 28 February 2014.

Submit or recommend next manuscript to SCIRP and we will provide best service for you:

Accepting pre-submission inquiries through Email, Facebook, LinkedIn, Twitter, etc. A wide selection of journals (inclusive of 9 subjects, more than 200 journals)

Providing 24-hour high-quality service

User-friendly online submission system

Fair and swift peer-review system

Efficient typesetting and proofreading procedure

Display of the result of downloads and visits, as well as the number of cited articles Maximum dissemination of your research work

Submit your manuscript at: http://papersubmission.scirp.org/

Or contactwjet@scirp.org 